\title{
Variation in the hatching response of Ochlerotatus albifasciatus egg batches (Diptera: Culicidae) in temperate Argentina
}

\section{Raúl Ernesto Campos ${ }^{+}$, Victoria Elena Sy}

\author{
Instituto de Limnología “Dr. Raúl A. Ringuelet”, Universidad Nacional de La Plata, CC 712, (1900) La Plata, Argentina
}

Egg hatching of winter-collected Ochlerotatus albifasciatus was studied for six months. Batches of eggs were divided into two groups, one of them was stored in the laboratory at $23^{\circ} \mathrm{C}$ and $12: 12$ photoperiod, and the other in the field under dead leaves. Every month, from July to December, eggs from the two groups were flooded under both laboratory and field conditions. Unhatched eggs were returned to the original condition and flooded two more times separated by ten-day intervals. Results show that egg diapause is expressed in different intensities, not only on eggs exposed to different conditions but also in those exposed to the same condition, even when they were laid by the same female. Successive inundations yielded incomplete hatches of eggs, and favored the hatching response in the next flooding. Low environmental temperatures before and during the flooding depressed hatching response. This shows that eggs need a warm period before flooding as well as warm temperatures during flooding, to hatch. As drought period was longer hatching response increased, but this was also accompanied by warmer environmental conditions. The experiment performed in laboratory did not show that increment. Field studies showed that a layer of dead leaves protected eggs from extreme temperatures.

Key words: Culicidae - Ochlerotatus albifasciatus - floodwater mosquito - egg dormancy - diapause - installment hatching Buenos Aires - Argentina

The floodwater mosquito Ochlerotatus albifasciatus (Macquart) occurs throughout Argentina, Bolivia, Chile, Paraguay, Uruguay, and Brazil (Forattini 1965, Forattini et al. 1988) from tropical to temperate areas. This mosquito was incriminated in 1982 as a vector of Western Equine Encephalitis (WEE) in Argentina (Mitchell et al. 1987). In addition, salivary allergens have been isolated from $O c$. albifasciatus which bite may cause allergic reactions in hypersensitive persons (Docena et al. 1999).

Temperature and rainfall conditions in temperate Buenos Aires allow several generations of $O$. albifasciatus, its abundance being higher during spring and fall (Maciá et al. 1995, Fontanarrosa et al. 2000, García \& Micieli 2000). Successive floodings of the same puddle hatched variable numbers of first instar larvae (García \& Micieli 2000, Campos \& Sy 2003). This variation was attributed to fluctuations of the flooding levels of larval sites (Maciá et al. 1995, García \& Micieli 2000), and it was speculated that subsequent peaks in abundance of adult O. albifasciatus occurred after prolonged drought as consequence of a large number of eggs accumulated (Fontanarrosa et al. 2000).

Although egg hatching depends on the water level at larval sites, intrinsic (endogenous rhythms) and extrinsic (hatching stimulus) factors determine hatchability after egg flooding (Clements 1992). As a consequence, the abundance of larvae in the aquatic habitat is influenced

Financial support: CONICET grant PIP 700/98

This paper is a scientific contribution no. 785 of the Instituto de Limnología "Dr. R. A. Ringuelet".

+Corresponding author: rcampos@ilpla.edu.ar

Received 4 August 2005

Accepted 13 December 2005 by these factors.

Under unfavorable conditions, $O$. albifasciatus eggs stay dormant as fully developed first instar larvae. In other Aedini with drought-resistant eggs such as Haemagogus, Aedes, and Psorophora, the dormancy ends when environmental conditions become favorable (Clements 1963). However, some viable eggs need more than one inundation to hatch. This behavior is known as installment hatching and was defined as partial hatch from one inundation to the next of viable mosquito eggs in response to suitable stimuli (Gillett 1955a). This behavior has been suggested as a reproductive strategy for long-term survival of multivoltine mosquitoes which have facultative egg diapause and develop in temporary pools exposed to irregular water fluctuations (Andreadis 1990). It is known that installment hatching varies greatly among species (Travis 1953, cited by Clements 1992), and between egg batches of the same species (Telford 1963). Variations occur within populations of the same species, and among eggs laid by the same female (Gillett 1955b).

The hatching behavior of $O$. albifasciatus has not been studied. However, during unrelated experiments conducted in our laboratory we observed irregular hatching of eggs from females captured from the field. Therefore, we initiated the present study to determine: (1) the proportion of eggs hatched after exposure to different temperature conditions before and during flooding; (2) the effect of different drying periods on the hatchability of eggs; (3) the hatching response after three successive floodings.

\section{MATERIALS AND METHODS}

Female and egg collections - Eggs were obtained from O. albifasciatus females collected with a manual aspirator at Pereyra Iraola Provincial Park, (34 $51^{\circ} \mathrm{S}$; 5 58 $08^{\prime} \mathrm{W}$ ) Buenos Aires Province, Argentina (for description of the area see Campos \& Sy 2003) on 3rd June 2003. 
Adult mosquitoes were transferred to $0.50 \times 0.50 \times$ $0.50 \mathrm{~m}$ cages kept in an insectary at room temperature (range: $18-22^{\circ} \mathrm{C}$ ) and a light-dark cycle of $12: 12 \mathrm{~h}$. Adult females were blood fed one time on a human host and individually isolated in tubes of $6 \times 3 \mathrm{~cm}$. The bottoms of the tubes were provided with a cotton pad covered by a piece of paper towel and moistened with distilled water. A cotton pad, placed on the top of the tube, was soaked in $10 \%$ sucrose solution. After oviposition, eggs from each female were transferred on top of a moist cotton pad and paper towel to individual Petri dishes $(50 \times 9 \mathrm{~mm}$ with a tight lid).

Experimental design and procedure - Two groups, each containing 42 batches were used. Each batch consisted in the total number of eggs laid by a single female. The first group was maintained in the laboratory at $23 \pm$ $2^{\circ} \mathrm{C}$ and 12:12 (L: D) photoperiod, condition similar to those found during spring and fall in natural sites (Campos \& Sy 2003). The second group of batches was stored in the field on the ground, and covered with dead leaves simulating a dry pool. Environmental maximum and minimum temperatures (accuracy of $0.1^{\circ} \mathrm{C}$ ) were recorded daily at the site, both from the air and under the dead leaves.

Every month from July to December, seven egg batches from each group were inundated. The eggs from each batch were subdivided into two subgroups of approximately equal numbers. Each subgroup was inundated under the two above mentioned conditions: in the laboratory (at $22^{\circ} \mathrm{C}$ and $12 \mathrm{~L}: 12 \mathrm{D}$ photoperiod) and in the field. The experimental conditions will be indicated as: LL (laboratory/laboratory); LF (laboratory/field); FL (field/laboratory), and FF (field/field). To stimulate hatching, eggs were transferred into Petri dishes containing a solution of 10 $\mathrm{mg}$ of yeast in $40 \mathrm{ml}$ distilled water, in which they remained submerged for $24 \mathrm{~h}$. After this time, hatched larvae were counted and unhatched eggs were returned to the original experimental conditions in the same Petri dishes. These eggs were subsequently flooded three consecutive times separated by 10 -day intervals.

After the third flooding, unhatched eggs were checked for viability. Egg chorions were bleached with a commercial 50\% sodium hypochlorite solution. Embryos that were creamy white with eye spots, a hatching spine, and distinct abdominal segmentation were considered viable. Yellow-brown or red-brown embryos were considerate non-viable (McHaffey \& Harwood 1970).

Data analysis - Differences in the hatching response among the three fixed factors (experimental conditions, inundations and months), were analyzed by 3-way ANOVA. Percentage of hatched eggs from each batch was calculated as the number of larvae after flooding/ number of viable eggs (hatched and un-hatched) $\times 100$, and each batch was treated as a replicate (Parker 1988). These percentages were arcsine-transformed before ANOVA using the Freeman-Tukey's transformation. When significant differences were detected by ANOVA, multiple comparisons of means were made using Tukey's honestly significant differences test for unequal data (Zar 1996).

\section{RESULTS}

From 140 O. albifasciatus egg batches collected, 6 $(4.3 \%)$ were infertile and $56(40 \%)$ were contaminated by fungus, collapsed, or hatched prior to or during the experiment, and therefore eliminated from further consideration.

The number of eggs per batch used in the experiment, ranged from 20 to 125 (Mean $=73.3 ;+\mathrm{SD}=20.3 ; \mathrm{n}=78$ ) from a total of 4222 eggs. After the third inundation $80.4 \%$ of eggs had hatched, and from the remaining unhatched eggs $81.5 \%$ contained fully formed embryos. Among the non-viable eggs only two had red-brown embryos with abdominal segments partially collapsed. The rest of them had no sign of embryo inside and were interpreted as no fertilized.

The 3-way ANOVA showed highly significant effects of all independent variables and their interactions (Table I).

\section{TABLE I}

Three-way analysis of variance results for percentage of hatched eggs of Ochlerotatus albifasciatus under four experimental conditions and three consecutive inundations over six months. $\mathrm{P}<0.001$ for all sources

\begin{tabular}{lrrr}
\hline Source & \multicolumn{1}{c}{ df } & \multicolumn{1}{c}{ MS } & \multicolumn{1}{c}{ F } \\
\hline Treatment (Treat.) & 3 & 1023 & 9.66 \\
Month & 5 & 1440.6 & 13.61 \\
Inundation & 2 & 115843.2 & 1094.30 \\
Treat. $\times$ Month & 15 & 524.3 & 4.95 \\
Treat. $\times$ Inundation & 6 & 1593.9 & 15.06 \\
Month $\times$ Inundation & 10 & 5962.7 & 56.33 \\
Treat. $\times$ Month $\times$ Inundation & 30 & 917.7 & 8.67 \\
Error & 393 & 105.9 & \\
\hline
\end{tabular}

\section{Effect of three successive inundations on hatchability}

LL treatment - In all months, mean percentage of eggs hatched by the first inundation was higher than $70 \%$ and significantly higher than effected by the second and third floodings. Although mean percentages of eggs hatched by the second inundation were higher than by the third, these differences were not significant (Fig. 1).

FF treatment - In July, none of the three inundations hatched eggs. During August, the second inundation hatched the most eggs, but no significant differences were detected among mean percentages hatching. In September no significant differences were found between mean percentages hatching, although the third flooding yielded the least number of larvae. In the following months, the first inundation produced greater than $97 \%$ mean hatch, which was significantly higher than the mean percentages from the second and third floodings (Fig. 2).

FL treatment - During July, the mean percentages of eggs hatched increased from the first to the third inundation but were not significantly different. During August, hatching from the first inundation was significantly higher than from the second. From September to December, the 


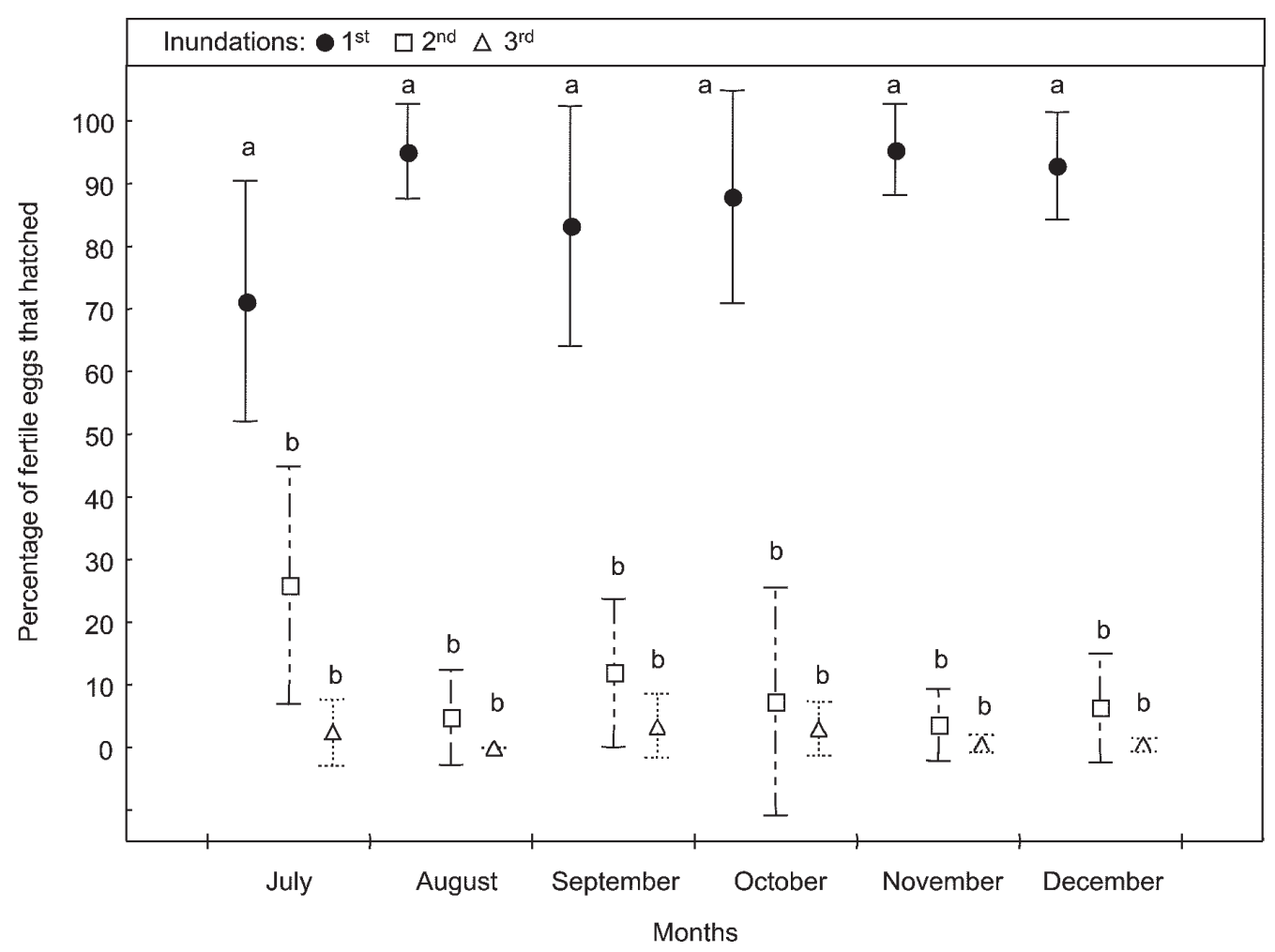

Fig. 1: monthly hatch (mean $\% \pm \mathrm{SD}$ ) of Ochlerotatus albifasciatus eggs after three consecutives inundations in treatments stored and inundated in laboratory (LL). Different letters denote significant differences detected by Tukey HSD test $(\mathrm{P}<0.05)$.

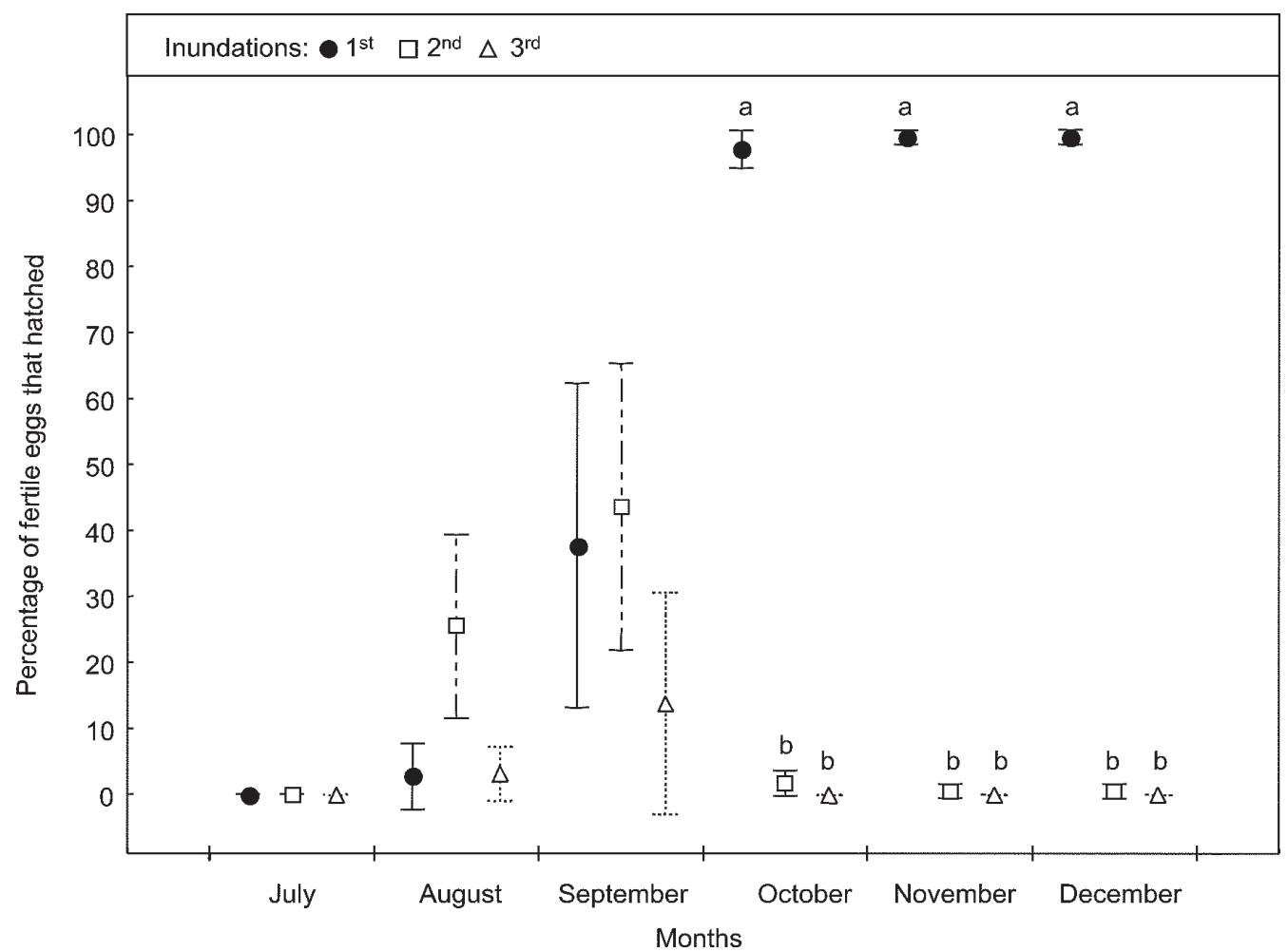

Fig. 2: monthly hatch (mean $\% \pm \mathrm{SD}$ ) of Ochlerotatus albifasciatus eggs after three consecutives inundations in treatments stored and inundated in the field (FF). Different letters denote significant differences detected by Tukey HSD test $(\mathrm{P}<0.05)$. 
mean percentages of eggs hatched by the first inundation were significantly higher than the means from the second or the third hatchings.

During September and October there were progressive decreases in the mean percentages hatched from the first to third inundation. In November and December more than $87 \%$ of eggs hatched in the first inundation, and percentages hatched were low during the second and third inundations (Fig. 3).

LF treatment - During July, the mean percent of eggs hatched increased from the first to the third inundation, but no significant differences were observed. In the succeeding months, significantly more eggs hatched from the first inundation compared to the second or third, differences being stronger from October to December (Fig. 4).

\section{Monthly hatching response on each treatment}

Percent of eggs hatched during the first inundation was used for this analysis, because results showed that most eggs hatched in response to this inundation.

LL treatment (Fig. 1) - No significant differences in the hatching response were detected among months (Tukey test: $\mathrm{P}>0.05)$. However, the mean percentage of eggs hatched in July was the lowest.

FF treatment (Fig. 2) - Hatching responses among months were significantly different (Tukey test: $\mathrm{P}<0.05$ ).
No egg hatched in July. In August, although some eggs hatched, the mean percentage was so low as to not show significant difference with July. Both months showed significant differences with the rest, but differences with September were lower than with October, November and December. Percent of eggs hatched during September was lower than in the following months.

FL treatment (Fig. 3) - Significant differences in the hatching response were detected among months (Tukey test: $\mathrm{P}<0.05)$. Mean percentage hatching in July was lower than in the remaining months. Mean percentage hatching in August was less than in November and December.

LF treatment (Fig. 4) - There were significant differences in the hatching response among months (Tukey test: $\mathrm{P}<0.05)$. The percentage of eggs hatched in July was less than in the other months. The mean percentage hatching in September was significantly less than in October, November or December.

\section{Monthly hatching response compared among treatments (Figs 1-4)}

In July, mean percentage of eggs hatched in the LL treatment was significantly higher than those in the other treatments (Tukey test: $\mathrm{P}<0.05$ ). In August, both LL and LF treatments, showed the highest mean percentages hatching, and significantly more than those stored in the

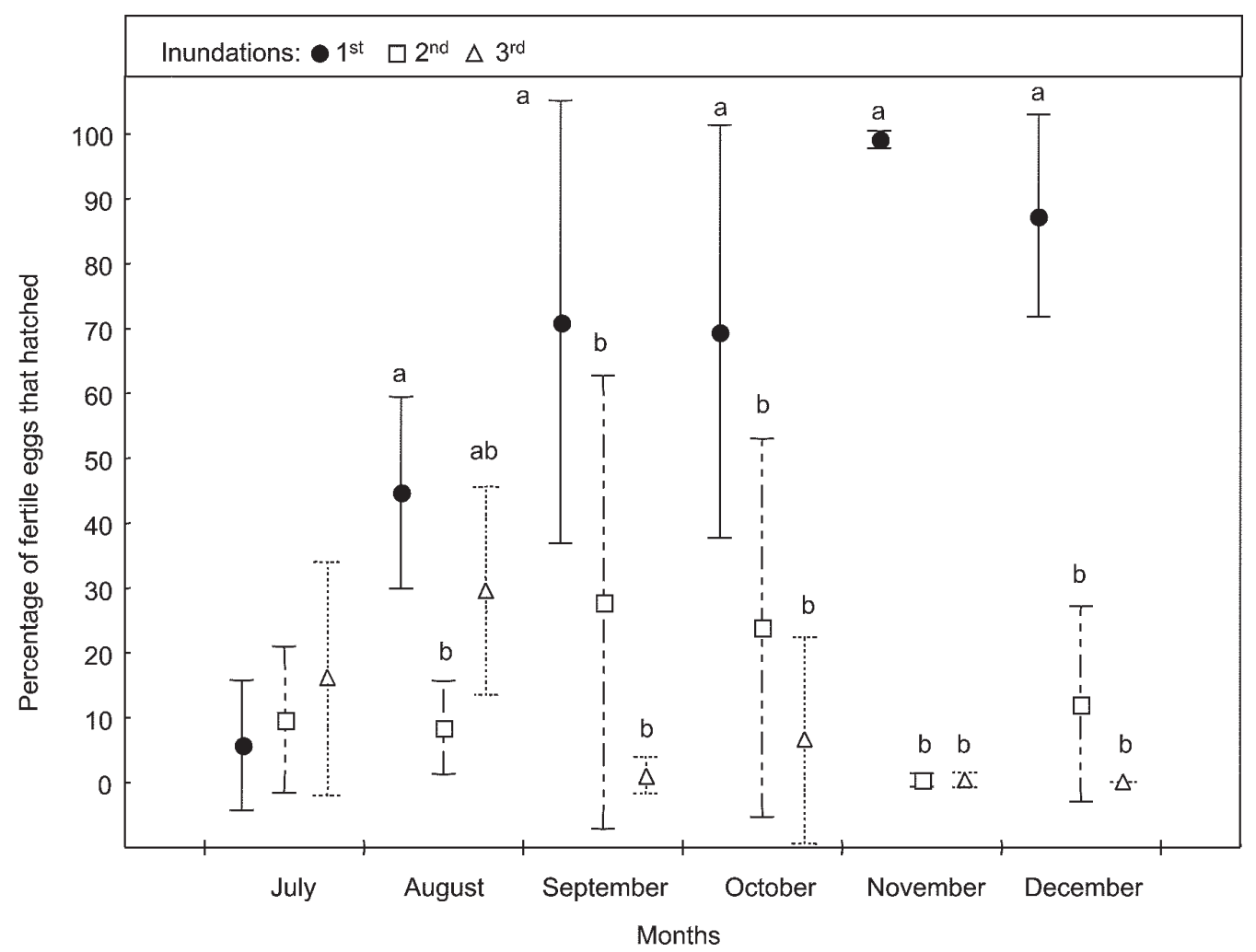

Fig. 3: monthly hatch (mean $\% \pm \mathrm{SD}$ ) Ochlerotatus albifasciatus eggs after three consecutives inundations in treatments stored in the field, and inundated in laboratory (FL). Different letters denote significant differences detected by Tukey HSD test (P < 0.05). 


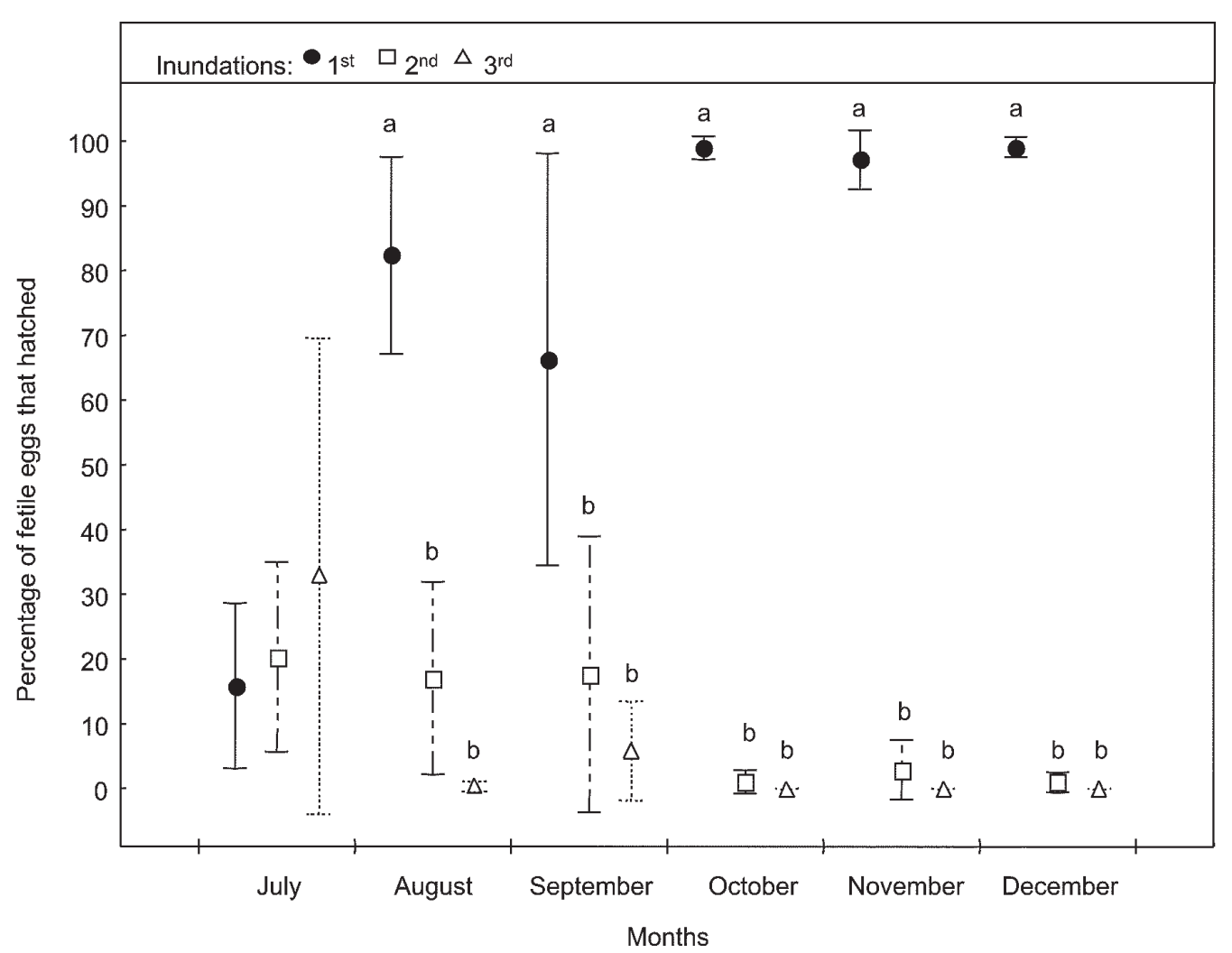

Fig. 4: monthly hatch (mean $\% \pm \mathrm{SD}$ ) of Ochlerotatus albifasciatus eggs after three consecutive inundations in treatments stored in laboratory, and inundated in the field (LF). Different letters denote significant differences detected by Tukey HSD test $(\mathrm{P}<0.05)$.

field $(\mathrm{P}<0.05)$. On the other hand, the mean hatching response in the FF treatment was significantly lower $(\mathrm{P}<$ 0.05) than in the FL. In September, significant differences were detected between LL and FF treatments $(\mathrm{P}<0.05)$. But neither of these mean percentages were significantly different from FL and LF. In October, mean percentage hatching in the FL treatment was the lowest, but not significantly different from the other treatments. In November and December, mean percentages hatching were higher than $87 \%$ in all treatments, and no significant differences were found among treatments.

\section{Unhatched viable eggs after the third flooding}

Unhatched viable eggs were recorded in all treatments (Table II). The highest number of unhatched eggs was found during July in all treatments except for LL, which showed a low percentage of unhatched eggs in all months. In field-stored treatments, mean percentages of unhatched eggs during the first two months were higher than in the others. In the LF treatment only July showed pronounced differences from the other months.

\section{Air and dead leaves temperatures}

Temperatures during the experiment, were more extreme in the air (Range: -1.5 to $33.5^{\circ} \mathrm{C}$ ) than in the dead leaves (Range: 8.1 to $30.1^{\circ} \mathrm{C}$ ). The same was observed for the mean temperature on each particular month (Fig. 5). In addition, differences between daily maximum and mini- mum temperatures were lower in the dead leaves than in the air.

\section{DISCUSSION}

Since females used in our study were collected in fall, it is possible that the short daylength and the low temperatures induced females to lay diapausing eggs (Wilson \& Horsfall 1970). However, in the LL treatment more than $70 \%$ of eggs hatched after the first flooding. This high hatching rate could be because fewer eggs entered diapause in laboratory-stored treatments, where they were exposed to $23^{\circ} \mathrm{C}$ and $12: 12$ photoperiod immediately after laying. A similar behavior was observed in Ochlerotatus dorsalis by Khelevin (1958). This author found that eggs exposed for 11 days to $16-17^{\circ} \mathrm{C}$ and then transferred to higher temperatures entered diapause, whereas eggs exposed only 6 days to low temperature did not enter diapause.

Some of the eggs from the LL treatments which did not hatch during the first inundation, hatched after the second and third. Perhaps those eggs had different diapause intensities (Danks 1987), and the exposure to an inundation between droughts was enough to end diapause.

When eggs stored in the laboratory were exposed to cold temperatures during inundation (LF treatment during July) only $15 \%$ hatched, a very low percentage compared with the LL treatment (70\%). This shows that some 
TABLE II

Percentage of unhatched viable eggs of Ochlerotatus albifasciatus after three consecutive inundations

\begin{tabular}{llccc}
\hline & \multicolumn{4}{c}{ Treatments } \\
\cline { 2 - 5 } Months & LL & FF & FL & LF \\
\hline July & 0.6 & 100 & 75.1 & 39.7 \\
August & 0 & 68.9 & 18.3 & 0.4 \\
September & 1.7 & 3.8 & 0 & 9.1 \\
October & 2.3 & 0.5 & 0 & 0 \\
November & 0.3 & 0 & 0 & 0 \\
December & 0.5 & 0 & 0.4 & 0 \\
\hline
\end{tabular}

F: field; L: laboratory

eggs hatch if temperatures during inundations are warm, but they fail to hatch in cold temperatures. In August and September, percentages hatching were higher than $60 \%$, and higher than $90 \%$ in October. It is possible that the increase in the hatching response was a result of higher temperatures during inundations, which in October reached values similar to the laboratory.

Hatching response of treatments stored in the field, was low during the cold months, but increased as days warmed. In July, no hatching was recorded in FF treatment and only $6 \%$ of eggs hatched in FL, showing that most eggs were in diapause. The few eggs that hatched in FL might have had a less intense diapause than the remainder. In August, $90 \%$ of eggs that failed to hatch in FF were not all in diapause. A 45\% hatching rate in FL showed that some eggs were prepared to hatch if temperatures during flooding were favorable. In September and October, percent of hatching was near $70 \%$ and increased even more in November and December. The progressive increase in environmental temperatures could be one of the factors favoring higher hatching rates in later months.

Comparing the hatching response by month, differences were found between treatments in July, August and September but not in later months. These differences suggest that diapause of $O$. albifasciatus eggs in temperate areas is quite short, and that hatching of this species in October is a result of post-diapause eggs prepared to hatch under favorable temperatures.

When eggs were exposed to successive inundations, installment hatching was observed in all treatments, and more evident during the initial months of the experiment. Eggs stored and flooded at $23^{\circ} \mathrm{C}$ showed this behavior mainly during the first month. Among eggs stored and/or flooded at lower temperatures, installment hatching was observed until the fourth month. Thus, batches of eggs laid during fall by $O$. albifasciatus and subjected to successive inundations during winter and early spring, would leave some eggs that will hatch during late spring, when conditions in larval sites are more favorable (Fontanarrosa et al. 2000). Erratic hatchings observed in other Aedini (e.g.: Woodard \& Chapman 1970, Logan et al. 1991) were interpreted as a strategy to increase survivorship in species inhabiting intermittent pools (Andreadis 1990), such as those used by $O$. albifasciatus.

On the other hand, results suggest that hatching of $O$. albifasciatus during cold months would be a result of eggs exposed to warm temperatures during a short period before or during the inundation of the pool (e.g. sun shining on the pool, warm days after rainfall, and heat generated by the organic decomposition of the soil). Our results show that the decomposition of the leaves create a micro-climate, where differences between maximum and minimum temperature are less pronounced. This condition favors the acclimatization of the eggs when the air

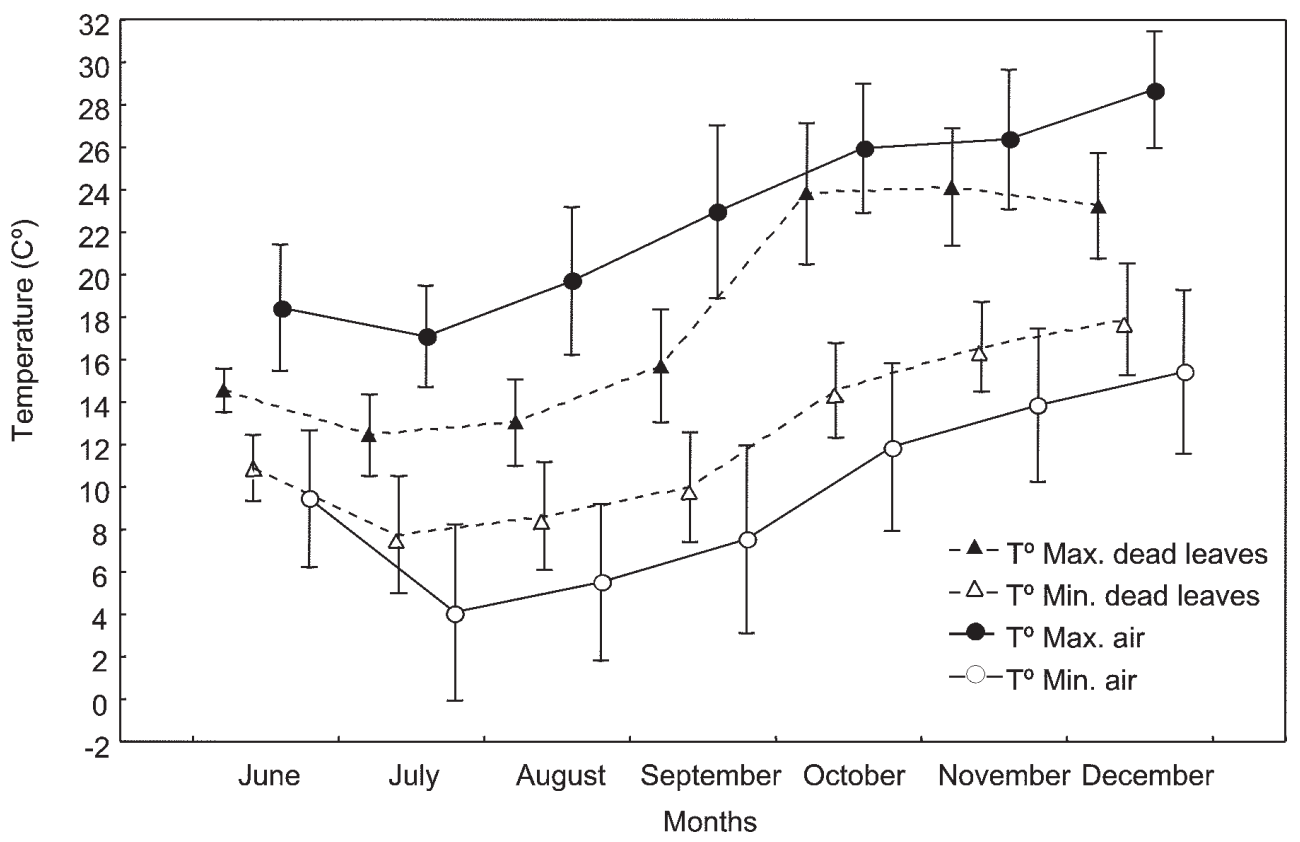

Fig. 5: monthly (mean $\pm \mathrm{SD}$ ) maximum and minimum temperatures of air and in dead leaves. 
temperature is extremely cold. In addition, during hot season, dead leaves provide the humidity necessary to avoid desiccation of the eggs.

We concluded then: 1) short daylengths and low temperatures could act upon $O$. albifasciatus females and induce egg diapause; 2) egg diapause is expressed in different intensities, even in eggs laid by the same female; 3 ) hatching response increase when the eggs are expose to long dry period, and warm temperature; 4) immersion of eggs for $24 \mathrm{~h}$ followed by a drought period favors hatching in the next immersion; 5) low temperatures during egg inundation decrease the hatching response.

\section{ACKNOWLEDGMENTS}

To LPLounibos (Florida Medical Entomology Laboratory, University of Florida, US), and WR Almirón (Universidad de Córdoba, Argentina) for helpful comments on earlier versions of the manuscript. To LP Lounibos for revision of the English text.

\section{REFERENCES}

Andreadis TG 1990. Observations on installment eggs hatching in the Brown Salt marsh mosquito, Aedes cantator. J Am Mosq Control Assoc 6: 727-729.

Campos RE, Sy VE 2003. Mortality in immatures of the floodwater mosquito Ochlerotatus albifasciatus (Diptera: Culicidae) and effects of parasitism by Strelkovimermis spiculatus (Nematoda: Mermithidae) in Buenos Aires Province, Argentina. Mem Inst Oswaldo Cruz 98: 199-208.

Clements AN 1963. The Physiology of Mosquitoes, Pergamon Press, London, 393 pp.

Clements AN 1992. The Biology of Mosquitoes, V. 1, Chapman \& Hall, London, 509 pp.

Danks HV 1987. Insect Dormancy: an Ecological Perspective, Biological Survey of Canada Monograph series 1, Ottawa, $439 \mathrm{pp}$.

Docena GH, Benítez P, Campos RE, Maciá A, Fernández R, Fossati CA 1999. Detection of allergens in Aedes albifasciatus mosquito (Diptera: Culicidae) extracts by immunological methods. Invest Allergol Clin Immunol 9: 165171.

Fontanarrosa MS, Marinone MC, Fisher S, Orellano PW, Schweigmann N 2000. Effects of flooding and temperature on Aedes albifasciatus development time and larval density in two rain pools at Buenos Aires University City. Mem Inst Oswaldo Cruz 95: 787-793.

Forattini OP 1965. Entomología Médica. 2. Culicini: Culex, Aedes e Psorophora, Univdersidade de São Paulo, São Paulo, $506 \mathrm{pp}$.

Forattini OP, Sallum MAM, Kakitani I 1988. Catálogo das coleções Entomológicas da Facultade de Saúde Pública da Universidade de São Paulo - ( $2^{\mathrm{a}}$ série II $)$ - Culicidae. Rev Saúde Pub 22: 519-547.
García JJ, Micieli MV 2000. Estacionalidad poblacional de los estados inmaduros de Aedes albifasciatus (Diptera: Culicidae) en la provincia de Buenos Aires, Argentina. Rev Biol Trop 48: 623-628.

Gillett JD 1955a. Variation in the hatching response of Aedes eggs (Diptera: Culicidae). Bull Entomol Res 46: 241-254.

Gillett JD 1955b. The inherited basis of variation in the hatching of Aedes eggs (Diptera: Culicidae). Bull Entomol Res 46: 255-265.

Khelevin NV 1958. The effect of environmental factors on the induction of embryonic diapause and on the number of generations in a season of Aedes caspius dorsalis Mg. (Diptera, Culicidae). Effect of temperature on the induction of embryonic diapause in Aedes caspius dorsalis Mg. Ent Rev 37: 19-35.

Logan TM, Linthicum KJ, Thande PC, Wagateh JN, Nelson GO, Roberts CR 1991. Egg hatching of Aedes mosquitoes during successive floodings in a Rift Valley fever endemic area in Kenya. J Am Mosq Control Assoc 7: 109-112.

Maciá A, García JJ, Campos RE 1995. Bionomía de Aedes albifasciatus y Ae. crinifer (Diptera: Culicidae) y sus enemigos naturales en Punta Lara, Buenos Aires. Neotrópica 4: 43-50.

McHaffey DG, Harwood RF 1970. Photoperiod and temperature influences on diapause in eggs of the floodwater mosquito Aedes dorsalis (Meigen) (Diptera: Culicidae). J Med Entomol 7: 631-644.

Mitchell CJ, Monath TP, Sabattini MS, Daffner JF, Cropp CB, Calisher CH, Darsie Jr RF, Jakob WL 1987. Arboviruse isolations from mosquitoes collected during and after the 1982-1983 epizootic of Western Equine Encephalitis in Argentina. Am J Trop Med Hyg 36: 107-113.

Parker BM 1988. Photoperiod-induced diapause in a North Carolina strain of Aedes sollicitans: photosensitivity of fully formed and developing embryos. J Am Mosq Control Assoc 4: 57-62.

Telford AD 1963. Consideration of diapause in Aedes nigromaculis and other Aedine mosquitoes (Diptera: Culicidae). Ann Entomol Soc Am 56: 409-418.

Travis BV 1953. Laboratory studies on the hatching of marshmosquito eggs. Mosq News 26: 405-415.

Wilson GR, Horsfall WR 1970. Eggs of floodwater mosquitoes XII. Installment hatching of Aedes vexans (Diptera: Culicidae). Ann Entomol Soc Am 63: 1644-1647.

Woodard DB, Chapman HC 1970. Hatching of flood-water mosquitoes in screened and unscreened enclosures exposed to natural flooding of Louisiana salt marches. Mosq News 30: 545-550.

Zar JH 1996. Biostatistical Analysis, 3rd ed., Prentice Hall, New Jersey, 718pp. 